\title{
Beyond Influencer Credibility: The Power of Content and Parasocial Relationship on Processing Social Media Influencer Destination Marketing Campaigns
}

\author{
Yi Xuan Ong $^{1}$, Tao Sun ${ }^{1(\Phi)}$, and Naoya Ito ${ }^{2}$ \\ ${ }^{1}$ Graduate School of International Media, Communications and Tourism \\ Studies, Hokkaido University, Sapporo, Japan \\ ${ }^{2}$ Research Faculty of Media and Communications, Hokkaido University, \\ Sapporo, Japan
}

\begin{abstract}
The power of social media influencers (SMIs) as effective endorsers for destinations and tourism products have been widely acknowledged. Despite being characterised as content generators by prior research, little has been done to examine how consumers perceive content produced by SMI, a key component of destination marketing campaigns. Moreover, parasocial relationship between SMI and the follower has been proven to enhance the persuasive impact of SMIs. Hence, this study aims to shed light on how consumers would assess the SMI and the content the SMI produced, as well as the effect of parasocial relationship on processing SMI destination marketing campaigns. Findings $(\mathrm{N}=501)$ have highlighted that argument quality of SMI content has a stronger direct impact on campaign attitude, destination image and travel intention, as compared to source credibility. With the application of the Elaboration Likelihood Model (ELM) as a framework, this study illuminates consumers' interaction with the SMI destination marketing campaign and extends prior studies in understanding the importance of SMI content and parasocial relationship as a significant tool for future destination marketing.
\end{abstract}

Keywords: Social medial influencer $\cdot$ Destination marketing $\cdot$ Parasocial relationship · Elaboration Likelihood Model

\section{Introduction}

Social media provided users with a convenient and instantaneous platform to share their content in various forms - text, images and videos [1]. Along with the rise of social media, the emergence of social media influencers (SMIs), and its use in marketing across various industries have been in the spotlight in both theory and practice. Studies have suggested the efficacy of SMI marketing in achieving various marketing outcomes such as enhancing brand awareness and purchase intention [2, 3].

This potential has been recognised by marketers and practitioners in the tourism industry, to leverage the power of SMIs for destinations and related products $[4,5]$. Existing SMI literature in tourism has examined the effectiveness of SMI marketing on 
destination image and travel intention with the application of various concepts such as self-congruity and source credibility [6,7]. Unlike celebrity endorsers, SMIs produce entertaining and informative content woven with their personalities and preferences, building a strong parasocial relationship with their followers, which exert an influence on their audience's decision making $[3,6,8]$. Yet, most studies on influencer marketing have focused on the attributes of the SMI based on source credibility $[3,6,8]$, or evaluated the campaign as a whole [7,9]. There is a research gap with regards to the content (i.e. argument quality) the SMIs have produced [10]. Since existing studies have suggested that trust for the SMIs and their content informativeness have a positive impact on consumers' travel decision journey [11, 12], and a positive effect on destination marketing [13], it is vital to investigate how parasocial relationship between the SMI and the follower would affect consumers' processing (based on source credibility and argument quality) of the SMI destination marketing campaign.

Considering the above, this study constructs a research mechanism that aims to (i) examine how self-congruity and parasocial relationship associate with perceptions of SMIs' argument quality and source credibility, and in turn (ii) how SMIs' argument quality and source credibility shape tourists' attitudes, destination image, and travel intention. The findings illuminate consumers' interaction with the SMI destination marketing campaign and extend prior studies in understanding the importance of SMI content as a significant tool for destination marketing amid the pandemic and beyond.

\section{Literature Review}

\subsection{Social Media Influencers in Tourism and Destination Marketing}

In recent years, there has been a rise in research on SMI marketing in tourism and hospitality. Gretzel [4] led the study of influencer marketing in tourism, highlighting the importance of SMIs as travel information sources and played a significant role in tourists' decision-making process. Empirical studies on SMI destination marketing campaigns such as $\mathrm{Xu}$ and Pratt [7], illustrated that SMI-destination congruence and SMI-consumer congruence positively affect consumers' attitudes toward the advertisement, which subsequently positively affects their attitude toward the destination and travel intention. Ong and Ito [9] elucidated the significance of SMI marketing campaign experience in forming consumers' attitude toward the campaign and destination image, which impact consumers' travel intention to the destination endorsed.

The latest studies investigating the impacts of SMIs on travel consumer behaviour have focused on the source credibility of the SMI based on the source credibility model. Jang et al. [6] illustrated source characteristics of SMI, such as the number of followers and engagement rate of SMI, as respective indicators of SMI's expertise and attractiveness which consequently positively impacts the effectiveness of the SMI campaign. Despite various studies having discussed that content of SMI is effective in forming consumers' image toward the marketed destination [12, 13], or positively affecting travel decision-making [14], little has been done to investigate the effects of the content produced by SMIs. Thus, this study would like to introduce a framework to 
expound on how attributes of the SMI and content produced by the SMI would impact the travel decision-making process of consumers.

\subsection{Hypothesis Development}

Elaboration Likelihood Model (ELM). Prior literature has used dual-route processes such as the ELM to explain consumers' information processing of an advertisement $[15,16]$. The ELM posits a two-route processing model, the central and the peripheral routes, in predicting persuasive messages [17]. The central route of persuasion occurs via one's cognitive effort of processing argument quality of the messages, undergoing thorough consideration of the relevant information [18]. Alternatively, the peripheral route takes place under processing affective features of messages, such as source credibility $[15,18]$. Unlike the source credibility model which has been employed by previous works to assess the impact of SMI on destination marketing, the organization of information processing into two distinct routes of persuasion by the ELM allows us to understand how consumers assess the SMI content, or the SMI respectively.

Self-Congruity. Defined as "the match between consumers' self-concept and the user's image of a given product, brand, store, etc." [19, p. 955], the self-congruity theory postulates that consumers are driven by their psychological motivation to express themselves by purchasing a product or service that is a match between their self-image with the product-user image of a product or service [20]. Looking at selfcongruity as a form of motivation of human behaviour [21], consumers may seek a match in the way they process information before elaborating the campaign based on either the argument quality of the campaign or the source characteristics of the SMI.

Based on the ELM, argument quality is defined as how one sees the persuasive strength of the persuasive argument or content embedded in the message [17, 22, 23]. Interestingly, there are very few researches that made use of argument quality to investigate the consumers' perception of SMI marketing advertisements. Since argument quality is a measurement of the persuasive strength of the content produced by the SMI, it should be used as a means of evaluating the SMI destination marketing campaign. With prior studies having illustrated the relationship between self-congruity and source credibility based on the congruence of self-SMI image [24], it is possible to deduce that consumers who preferred to make use of more cognitive effort, and are more involved in scrutinizing the information, would have formed a congruence between self and the SMI content and undergo the central route of information elaboration, focusing on the quality of the information provided [17, 25].

On the other hand, in the framework of ELM, individuals tend to take the peripheral route when they have less motivation, making use of lesser cognitive effort to evaluate the information $[17,26]$. By undertaking the peripheral route, consumers tend to evaluate based on peripheral cues, such as the brand image or source credibility [17]. Extant studies have approached SMIs' source credibility by considering attractiveness, expertise, and trustworthiness [27-29]. Of these, Yoon and Kim [27] have pointed out that self-congruity at an early phase of advertisement perception is able to influence consumers' perception of SMI credibility. If the consumer seeks self-consistency as 
someone who travels to a destination marketed by a SMI based on the source cues of the SMI, it is likely to provide a shortcut for the consumer's information elaboration process, taking the peripheral route.

Therefore, with the above, this study would like to hypothesise that:

Hla: Self-Congruity positively affects perceived argument quality.

HIb: Self-congruity positively affects perceived source credibility.

Parasocial Relationship between SMI and Followers. Defined as a unilateral relationship that a media audience developed for a media character [30-32], the parasocial relationship between the SMI and the follower is developed through their everyday online interactions, culminating trust for the SMI and reliance on the SMI as a credible information source that influences followers' consumption decision-making [11, 13, 31]. Recently, the concept of parasocial relationship on social media between the SMI and their followers have been examined [3, 8, 29, 33]. Shan et al. [33] have suggested that perceived image congruence between the SMI and the consumer as the initiation of the parasocial relationship. The study further proved that self-SMI congruence is a strong indicator of the strength of parasocial relationship [33]. Thus,

H1c: Self-congruity positively affects Parasocial Relationship.

Existing studies such as Breves et al., [8, 24] have illuminated that parasocial relationship is equivalent to the halo effect, enhancing source credibility, especially on trustworthiness, which in turn positively affects brand credibility and purchase intention. Similarly, Yuan and Lou [29] also illustrated that parasocial relationship positively mediates source credibility on consumers' interest in SMI-marketed products. That is, followers are more likely to form a stronger parasocial relationship with SMI whom they consider attractive and similar to themselves and this parasocial relationship, in turn, leads to greater interest in the products promoted by the influencers. Hence, it can be inferred that a stronger parasocial relationship with the influencer, followers would tend to perceive the SMI as attractive, an expert, and trustworthy.

Yet, little has been done to understand how followers' parasocial relationship with the SMI would affect the argument quality of the SMI marketing campaign. While extant studies have highlighted that parasocial relationship is likely to enhance the source credibility of the SMI, parasocial relationship can also enhance argument quality $[3,11]$. Based on the ELM, when elaboration involvement with the product or service, or in this case, the parasocial relationship with the SMI, followers may also undertake the central route of processing via argument quality. Hence, we propose:

H2a: Parasocial Relationship positively affects perceived argument quality.

H2b: Parasocial Relationship positively affects perceived source credibility.

Additionally, previous studies also indicated that processing peripheral cues can generate increased motivation, ability, or even consistency to consumers' actual selfconcept, leading to more comprehensive information processing via the central route $[18,34]$. Recent studies have also investigated the possibility of a two-step processing, where that peripheral route-persuasion is undergone first for consumers who are more likely to look out at source cues of the SMI in the campaign, followed by a central route-persuasion for in-depth scrutiny of the campaign content [17, 25, 35]. This is evident in current works where source credibility of the SMI would positively affect how consumers process the content of the SMI [3, 8]. As such, we propose: 
H3: Perceived source credibility positively affects perceived argument quality.

Affective Evaluation and Behavioural Intention. With a higher argument quality perceived by the consumer, it would mean that the information is persuasive and informative, generating positive attitudinal dispositions toward the SMI campaign [23]. Similarly, consumers would tend to perceive the marketing campaign as positive if it comes from a source that is perceived as credible, knowledgeable, and attractive [27, 28]. In the current study, the audience of the SMI destination marketing will evaluate the campaign based on argument quality and/or source credibility, which forms an attitude toward the campaign. Prior studies also revealed that after the exposure of the campaign, the consumers would form an attitude toward the campaign, which thereby affects the brand attitude and purchase intention [7, 9].

The appropriate use of SMI as endorsers of destination marketing, or having a good SMI-destination congruity is influential to the forming destination image [7]. As evident from previous studies, SMIs are significant in enhancing the campaign experience of destination marketing, which result in forming a positive attitude toward the campaign and positive attitude and/or image formed of the destination marketed, becoming important predictors for travel intention [7, 9]. Looking at the current state of a global pandemic, there is no sight of when international leisure travel will happen, with even the possibility of travel fear [36]. Therefore, this study would like to understand how consumers, while still amid the COVID-19 pandemic, would travel after the pandemic is over. Based on prior literature, it can be hypothesised that:

H4: Perceived argument quality positively affects the (a) attitude toward the SMI campaign, (b) destination image, and (c) post-COVID-19 travel intention.

H5: Perceived source credibility positively affects the (a) attitude toward the SMI campaign, (b) destination image, and (c) post-COVID-19 travel intention.

H6: Campaign attitude positively affects consumers' destination image of the marketed destination.

H7: Consumers' destination image of the marketed destination positively affects the post-COVID-19 travel intention of the marketed destination.

Therefore, this study would like to propose the hypothesised model (Fig. 1), to test the causal and dynamic paths in processing and perceptions toward the SMI destination marketing campaign.

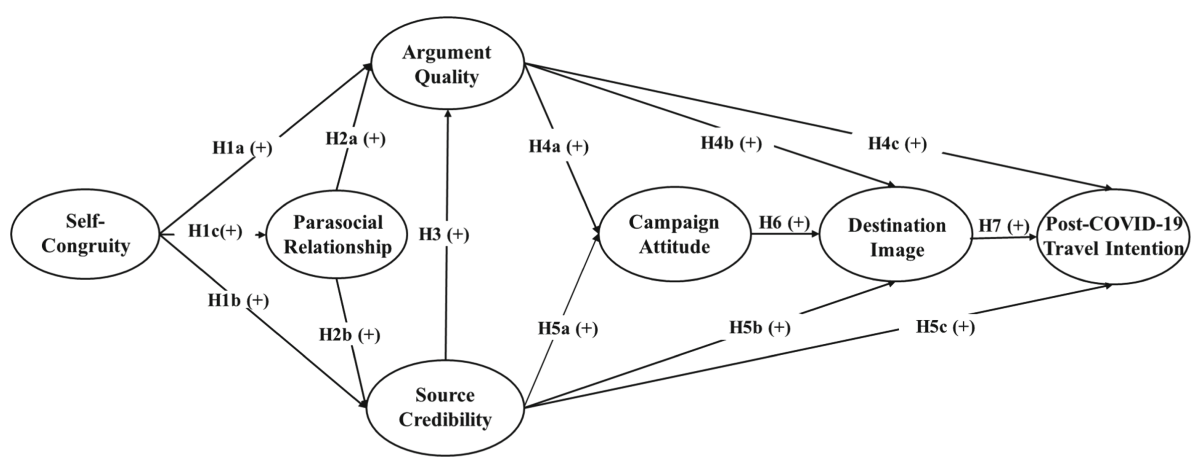

Fig. 1. Research model. 


\section{Methodology}

\subsection{Data Collection and Analysis}

A web-based questionnaire was distributed in May 2021 to followers of SMIs with the help of a local market research firm in Singapore. Singapore was chosen as it is one of the world's top outbound tourist source nations, [37], as well as one of the key markets that Japan has been actively marketing through SMIs to attract inbound tourists to second-tier destinations within the country [38, 39]. SMI destination marketing campaign usually involves various contents produced by the SMI, targeting consumers aged 18 to $35[7,10]$. Recently, Instagram has been the social media platform where DMOs leveraged SMIs as it allowed imagery and textual content to reach out to the target audience of SMIs. Thus, a stimulus of a SMI destination marketing campaign promoting Japan on Instagram was adapted, featuring Singapore's top travel SMI, Xin Lin Khaw (@xinlinn).

Instruments were developed from existing literature with the use of a seven-point Likert scale ( 1 = strongly disagree; 7 = strongly agree). Items measuring self-congruity and perceived source credibility of SMI were adapted from Yoon and Kim [27], while items for perceived argument quality were derived from Filieri and McLeay [26]. The affective evaluation scale and measures for behavioral intention were adapted from Ong and Ito [9], and $\mathrm{Xu}$ and Pratt [7]. Measurement item for parasocial relationship were developed from existing literature [29, 31, 32].

SPSS was first used for descriptive analysis, then partial least squares structural equation modelling (PLS-SEM) was applied to test the measurement model and structural model. PLS-SEM is appropriate for predictive research and has flexible abilities in handling complex models, small sample sizes, and non-normal data [40]. Given this study is predictive, PLS-SEM was selected. Utilizing SmartPLS (version 3.2.9), the measurement model and structural model were assessed with the PLS algorithm and bootstrapping (5000 subsamples), respectively.

\section{Results}

\subsection{Descriptive Statistics}

A total of 501 valid responses were obtained after a month of data collection. Out of 501 respondents, 255 are female, 243 are male, and three respondents identified as nonbinary. The sample is also representative of Singapore's multiracial composition, with 78.2\% Chinese, $11.8 \%$ Malay, 6.6\% Indian, and 3.4\% Eurasian/Others. $7.6 \%$ of the respondents are aged $18-19,41.9 \%$ aged $20-25,16.6 \%$ within the $26-30$ age range, $17.0 \%$ who are $30-35$, and $17.0 \%$ who are 35 and above.

\subsection{Measurement Model}

The measurement model was evaluated by internal consistency reliability, convergent validity, and discriminant validity of the constructs. As presented in Table 1, the indicator loadings ranged from 0.765 to 0.958 , greater than the threshold value of 0.708 
Table 1. Measurement model for constructs.

\begin{tabular}{|c|c|c|c|}
\hline Construct and item & Mean & SD & Loading \\
\hline \multicolumn{4}{|c|}{ Self-congruity $(S C O)$ (Cronbach's $\alpha=0.950, \mathrm{CR}=0.964, \mathrm{AVE}=0.869)$} \\
\hline \multicolumn{4}{|l|}{ Travelling to a destination recommended by an SMI is } \\
\hline (1) consistent with how I see myself & 3.986 & 1.547 & 0.922 \\
\hline (2) consistent with how I like to see myself & 4.142 & 1.589 & 0.933 \\
\hline (3) consistent with how I believe others see me & 3.804 & 1.562 & 0.934 \\
\hline (4) consistent with how I would like others to see me & 3.904 & 1.629 & 0.939 \\
\hline
\end{tabular}

Parasocial Relationship (PSR) (Cronbach's $\alpha=0.938, \mathrm{CR}=0.956$, AVE $=0.843$ )

\begin{tabular}{l|l|l|l|} 
(1) If there is a content related to the SMI on any media, I & 4.561 & 1.543 & 0.917
\end{tabular} would read it

(2) When the SMI shows me how he/she feels about the destination, it helps me make up my own mind about the destination

(3) I can rely on information I get from my favourite SMI

\begin{tabular}{|l|l|l|}
\hline 4.579 & 1.527 & 0.924 \\
\hline 4.565 & 1.472 & 0.904 \\
\hline 4.503 & 1.529 & 0.928 \\
\hline
\end{tabular}

(4) The SMI makes me feel comfortable, as if I am with a friend

Source Credibility (SC) (Cronbach's $\alpha=0.959, \mathrm{CR}=0.965, \mathrm{AVE}=0.778)$

This SMI appears to

\begin{tabular}{|l|l|l|l}
\hline (1) be attractive & 4.956 & 1.430 & 0.765 \\
\hline (2) be reliable & 4.585 & 1.331 & 0.917 \\
\hline (3) be sincere & 4.579 & 1.400 & 0.897 \\
\hline (4) be knowledgeable & 4.465 & 1.465 & 0.914 \\
\hline (5) be experienced & 4.423 & 1.459 & 0.913 \\
\hline (6) be expert & 4.178 & 1.473 & 0.89 \\
\hline (7) reflect my own interests & 4.343 & 1.473 & 0.887 \\
\hline (8) have common interests with me & 4.439 & 1.475 & 0.862
\end{tabular}

Argument Quality $(A Q)$ (Cronbach's $\alpha=0.950, \mathrm{CR}=0.995, \mathrm{AVE}=0.751$ )

The information I get through the SMI campaign

\begin{tabular}{|l|l|l|l}
\hline (1) is relevant as it matches my needs & 4.407 & 1.506 & 0.907 \\
\hline (2) is appropriate for satisfying my needs & 4.443 & 1.469 & 0.827 \\
\hline (3) is easy to read & 4.938 & 1.362 & 0.828 \\
\hline (4) is easy to understand & 5.004 & 1.374 & 0.859 \\
\hline (5) is correct & 4.605 & 1.349 & 0.844 \\
\hline (6) enables me to objectively understand the destination & 4.305 & 1.550 & 0.889 \\
\hline (7) provides me with information that I couldn't get elsewhere & 4.212 & 1.592 & 0.907 \\
\hline
\end{tabular}

Campaign Attitude (CA) (Cronbach's $\alpha=0.950, \mathrm{CR}=0.968, \mathrm{AVE}=0.909$ )

This campaign is

\begin{tabular}{l|l|l|l}
\hline (1) interesting & 4.747 & 1.436 & 0.950 \\
\hline (2) good & 4.683 & 1.356 & 0.958 \\
\hline (3) likable & 4.860 & 1.346 & 0.952 \\
\hline
\end{tabular}


Table 1. (continued)

\begin{tabular}{|c|c|c|c|}
\hline Construct and item & Mean & SD & Loading \\
\hline \multicolumn{4}{|c|}{ Destination Image $(D I)$ (Cronbach's $\alpha=0.944, \mathrm{CR}=0.964, \mathrm{AVE}=0.899)$} \\
\hline \multicolumn{4}{|l|}{ The destination is } \\
\hline (1) Favourable vs Unfavourable & 4.936 & 1.312 & 0.950 \\
\hline (2) Positive vs Negative & 5.022 & 1.289 & 0.956 \\
\hline (3) Interesting vs Boring & 4.904 & 1.391 & 0.940 \\
\hline \multicolumn{4}{|c|}{ Post-COVID Travel Intention $(P C T I)($ Cronbach's $\alpha=0.950, \mathrm{CR}=0.964, \mathrm{AVE}=0.869)$} \\
\hline $\begin{array}{l}\text { (1) I am very likely to visit the destination recommended in the } \\
\text { influencer campaign when international travel resumes }\end{array}$ & 4.645 & 1.552 & 0.938 \\
\hline $\begin{array}{l}\text { (2) I definitely will visit the destination recommended in the } \\
\text { influencer campaign in the near future }\end{array}$ & 4.487 & 1.538 & 0.944 \\
\hline $\begin{array}{l}\text { (3) I plan to visit the destination recommended in the } \\
\text { influencer campaign in my next trip }\end{array}$ & 4.441 & 1.516 & 0.936 \\
\hline $\begin{array}{l}\text { (4) The influencer campaign makes me want to travel to the } \\
\text { destination in post-COVID situation }\end{array}$ & 4.559 & 1.597 & 0.912 \\
\hline
\end{tabular}

[40]. The values of Cronbach's alpha and composite reliability (CR) all exceeded 0.70, indicating sufficient construct reliability [40]. The values of average variance extracted (AVE) are between 0.751 to 0.909 , surpassing the threshold of 0.50 and building up the convergent validity. The heterotrait-monotrait ratio of correlations (HTMT) was applied to appraise the discriminant validity. Results have shown that the highest value of the HTMT score is 0.790 , below the recommended value of 0.85 [41]. Thus, satisfactory discriminant validity was achieved.

\subsection{Structural Model and Hypothesis Testing}

The structural model was assessed with a series of statistic indexes. The standardised root mean residual (SRMR) was 0.062 , lower than the stipulated criterion of 0.08 , suggesting a good model fit [41]. The inner and outer values of variance inflation factor (VIF) were less than 10, excluding the issues of multicollinearity [42]. The effect sizes $\left(f^{2}\right)$ of most paths exceeded 0.15 , demonstrating medium to large effects [43]. $R^{2}$ values of $0.19,0.33$ or 0.67 for endogenous constructs are described as weak, moderate or substantial [44]. The proposed research model manifested relatively moderate to substantial explanatory power (PSR: $28.1 \%$, AQ: $70.9 \%$, SC: $53.5 \%$, CA: $57.9 \%$, DI: 68.5\%, PCTI: 61.8\%). Values of Stone-Gaisser's $Q^{2}$ for endogenous constructs were calculated using the Blindfolding test; with $Q^{2}$ values exceeding the minimum requirement of zero $(0.234 \sim 0.610)$, implying good predictive relevance [43].

Table 2 shows the results of hypothesis testing. 12 out of 14 proposed paths were attested to be significant and supported. Only H1a and H5b were not supported. Posthoc analysis was executed to uncover any mediating effects on the non-significant hypotheses. Firstly, the association between $\mathrm{SCO}$ and $\mathrm{AQ}$ was found to be significant when mediated by PSR $(\beta=0.205, t=4.200,95 \%$ C.I. $=0.115-0.304)$, and SC 
$(\beta=0.173, t=4.261,95 \%$ C.I. $=0.040-0.111)$. Similarly, AQ $(\beta=0.214, t=4.463$, 95\% C.I. $=0.131-0.315)$ and CA $(\beta=0.077, t=2.130,95 \%$ C.I. $=0.015-0.157)$ were also proved to significantly mediate the relationship between SC and DI.

Table 2. Results of hypothesis testing.

\begin{tabular}{l|l|r|l|l|l}
\hline Hypothesis & Path & $\beta$ & $t$ Value & $f^{2}$ & Result \\
\hline H1a & SCO $\rightarrow$ AQ & 0.021 & $0.593^{\mathrm{ns}}$ & 0.001 & No \\
\hline H1b & SCO $\rightarrow$ SC & 0.335 & $5.370^{* * *}$ & 0.174 & Yes \\
\hline H1c & SCO $\rightarrow$ PSR & 0.530 & $12.158^{* * *}$ & 0.391 & Yes \\
\hline H2a & PSR $\rightarrow$ AQ & 0.387 & $4.495^{* * *}$ & 0.267 & Yes \\
\hline H2b & PSR $\rightarrow$ SC & 0.497 & $7.406^{* * *}$ & 0.382 & Yes \\
\hline H3 & SC $\rightarrow$ AQ & 0.517 & $6.578^{* * *}$ & 0.428 & Yes \\
\hline H4a & AQ $\rightarrow$ CA & 0.632 & $8.499^{* * *}$ & 0.355 & Yes \\
\hline H4b & AQ $\rightarrow$ DI & 0.413 & $5.119^{* * *}$ & 0.150 & Yes \\
\hline H4c & AQ $\rightarrow$ PCTI & 0.271 & $3.261^{* * *}$ & 0.048 & Yes \\
\hline H5a & SC $\rightarrow$ CA & 0.156 & $2.071^{*}$ & 0.022 & Yes \\
\hline H5b & SC $\rightarrow$ DI & -0.029 & $0.565^{\mathrm{ns}}$ & 0.001 & No \\
\hline H5c & SC $\rightarrow$ PCTI & 0.174 & $2.522^{*}$ & 0.030 & Yes \\
\hline H6 & CA $\rightarrow$ DI & 0.493 & $7.597^{* * *}$ & 0.324 & Yes \\
\hline H7 & DI $\rightarrow$ PCTI & 0.419 & $6.345^{* * *}$ & 0.192 & Yes \\
\hline
\end{tabular}

Note. $\quad * p<0.05, * * p<0.01, * * * p<0.001 . \beta=$ Standardised regression weight. $f^{2}=$ Effect sizes. $\mathrm{SCO}=$ Self-congruity, $\mathrm{AQ}=$ Argument quality, PSR $=$ Parasocial relationship, $\mathrm{SC}=$ Source credibility; $\mathrm{CA}=$ Campaign attitude, $\mathrm{DI}=$ Destination image, PCTI $=$ Post-COVID travel intention. Yes $=$ Supported, No $=$ Unsupported

\section{Discussion}

\subsection{Theoretical and Practical Implications}

The Power of Parasocial Relationship between SMI and Followers. Findings have elucidated that the influences of PSR between SMI and followers are two-fold. Firstly, the current study has extended research by uncovering that PSR not only positively affects SC but also directly enhances the persuasive impact of the SMI content through AQ. Secondly, the non-significant direct effect of SCO on AQ has led to the discovery of two mediating effects by PSR and SC. The direct and mediating effect of PSR on AQ also show that PSR between SMI and the follower acts as a positive halo effect that not only enhances SC of SMI, but also AQ of SMI content. This illustrates the PSR between SMI and followers enhances involvement, which heightens motivation and confidence in evaluating the content, before proceeding to the next step of their decision-making $[25,35]$. The influence of PSR on AQ encourages consumers to undertake the central route of persuasion, resulting in more positive effects on affective 
evaluation and behavioural intentions. Similarly, the mediating effect of SC on AQ proposed the integral role SC plays in cognitive processing: as a filter for consumers, enhancing the persuasion impact in SMI content [8], before continuing on with the central route of persuasion. Considering the importance of PSR, destinations should continue to engage consumers despite the lack of travelling. SMIs could still engage followers with entertaining content to maintain strong PSR [12, 13, 45]. Destination marketers could still partner with SMIs by leveraging technology through virtual tours, online Zoom meetings to share expert tips, and keep followers engaged during COVID19 , building awareness and loyalty for destinations.

More than Just Influencer Credibility. Findings have illustrated the importance of AQ with stronger direct effects on tourists' CA, DI, and PCTI as compared to that of SC. Similarly, AQ has also been uncovered to be a significant mediator in the relationship between SC and DI. Both findings highlight the importance of the content quality of the SMI. Unlike existing studies that have evaluated impacts of SMI based on the source credibility model, the current study has used the ELM as a framework that gives us insights into how consumers assess the content and the SMI based on AQ and SC, respectively. Especially when SMIs are no longer just an endorser, but also a content creator who is proactive in the co-creation of the storytelling $[3,5,45]$, the visual and textual presentation of the destination in the SMI's content could elicit engagement with the campaign more effectively, inducing a positive image of the marketed destination, as compared to attributes of SC of the SMI [46]. Findings of the current study also corroborated with Asan's [13] suggestion that "engaging and aesthetic experiences" (p.12) shared through SMI content have a positive effect on destination marketing. Content has become crucial for both content creators (SMIs) and marketers. Particularly with the increase in the amount of time spent on social media during the pandemic, consumers would tend to scrutinise more on the quality of content. Therefore, future studies should expound further on evaluating the marketing content of SMIs or even new measures to study the effectiveness of content. With the above, we propose that practitioners should not just focus on indicators of SC (e.g. the number of followers, attractiveness of SMI) as criteria for selecting the right SMI for their marketing campaigns [45]. Content quality should be held as an important criterion for choosing the appropriate SMI since good content would develop positive campaign attitudes, destination image and travel intention to the marketed destination. Nevertheless, SC is still an essential criterion in evaluating the impacts of SMI destination marketing, as well as a requirement in SMI selection, as SC directly influences campaign attitude, travel intention, and enhances persuasion impact of their content.

\subsection{Limitations and Future Studies}

This study collected its data during COVID-19, which may showcase how the consumers perceive SMI destination marketing in the state of the pandemic. Future studies could compare the effects of SC and AQ of SMI destination marketing pre-COVID, during COVID-19, and post-COVID. Moreover, travel intention was tested in this study on the assumption that international travel has recovered; future research could explore the role of SMI may play in alleviating tourists' perceived travel risk. 


\section{References}

1. Cox C, Burgess S, Sellitto C, Buultjens J (2009) The role of user-generated content in tourists' travel planning behavior. J Hosp Market Manag 18(8):743-764

2. Hudders L, De Jans S, De Veirman M (2020) The commercialization of social media stars: a literature review and conceptual framework on the strategic use of social media influencers. Int J Advert 1-49

3. Lou C, Yuan S (2019) Influencer marketing: how message value and credibility affect consumer trust of branded content on social media. J Interact Advert 19(1):58-73

4. Gretzel U (2018) Influencer marketing in travel and tourism. In Advances in social media for travel, tourism and hospitality: New perspectives, practice and cases, pp 147-156

5. Nyangwe S, Buhalis D (2018) Branding transformation through social media and cocreation: lessons from Marriott international. In: Stangl B, Pesonen J (eds) Information and communication technologies in tourism 2018. Springer, Cham, pp 257-269

6. Jang W, Kim J, Kim S, Chun JW (2020) The role of engagement in travel influencer marketing: the perspectives of dual process theory and the source credibility model. Current Issues in Tourism 1-5

7. Xu X, Pratt S (2018) Social media influencers as endorsers to promote travel destinations: an application of self-congruence theory to the Chinese Generation Y. J Travel Tour Mark 35 (7):958-972

8. Breves P, Amrehn J, Heidenreich A, Liebers N, Schramm H (2021) Blind trust? The importance and interplay of parasocial relationships and advertising disclosures in explaining influencers' persuasive effects on their followers. Int J Advert 1-20

9. Ong YX, Ito N (2019) "I Want to Go There Too!" evaluating social media influencer marketing effectiveness: a case study of Hokkaido's DMO. In: Pesonen J, Neidhardt J (eds) Information and communication technologies in tourism 2019. Springer, Cham, pp 132-144. https://doi.org/10.1007/978-3-030-05940-8_11

10. Femenia-Serra F, Gretzel U (2020) Influencer marketing for tourism destinations: lessons from a mature destination. In: Neidhardt J, Wörndl W (eds) Information and communication technologies in tourism 2020. Springer, Cham, pp 65-78. https://doi.org/10.1007/978-3-03036737-4_6

11. Pop RA, Săplăcan Z, Dabija DC, Alt MA (2021) The impact of social media influencers on travel decisions: the role of trust in consumer decision journey. Current Issues in Tourism, $1-21$

12. Yilmaz M, Sezerel H, Uzuner Y (2020) Sharing experiences and interpretation of experiences: a phenomenological research on Instagram influencers. Curr Issue Tour 23 (24):3034-3041

13. Asan K (2021) Measuring the impacts of travel influencers on bicycle travellers. Current Issues Tourism 1-17

14. Magno F, Cassia F (2018) The impact of social media influencers in tourism. Anatolia 29 (2):288-290

15. Teng S, Khong KW, Goh WW, Chong AYL (2014) Examining the antecedents of persuasive eWOM messages in social media. Online Inf Rev 38(6):746-768

16. Xiao M, Wang R, Chan-Olmsted S (2018) Factors affecting YouTube influencer marketing credibility: a heuristic-systematic model. J Media Bus Stud 15(3):188-213

17. Petty R, Cacioppo J (1986) The elaboration likelihood model of persuasion. Adv Exp Soc Psychol 19:123-205

18. Kang J, Tang L, Lee JY (2015) Self-congruity and functional congruity in brand loyalty. J Hospital Tourism Res 39(1):105-131 
19. Kressmann F, Sirgy MJ, Herrmann A, Huber F, Huber S, Lee DJ (2006) Direct and indirect effects of self-image congruence on brand loyalty. J Bus Res 59(9):955-964

20. Sirgy MJ (1985) Using self-congruity and ideal congruity to predict purchase motivation. J Bus Res 13(3):195-206

21. Hung K, Petrick JF (2012) Testing the effects of congruity, travel constraints, and selfefficacy on travel intentions: an alternative decision-making model. Tour Manage 33(4):855867

22. Bhattacherjee A, Sanford C (2006) Influence processes for information technology acceptance: an elaboration likelihood model. MIS Q 805-825

23. Sussman SW, Siegal WS (2003) Informational influence in organizations: an Integrated approach to knowledge adoption. Inf Syst Res 53(9):1689-1699

24. Breves PL, Liebers N, Abt M, Kunze A (2019) The perceived fit between Instagram influencers and the endorsed brand: how influencer-brand fit affects source credibility and persuasive effectiveness. J Advert Res 59(4):440-454

25. Ong YX, Ito N, Li R, Sun T (2021) Review or the reviewer? Effects of self-congruity in processing online travel review. Travel and Tourism Research Association: Advancing Tourism Research Globally, vol 33

26. Filieri R, McLeay F (2013) E-WOM and accommodation: an analysis of the factors that influence travelers' adoption of information from online reviews. J Travel Res 53(1):44-57

27. Yoon D, Kim YK (2016) Effects of self-congruity and source credibility on consumer responses to coffeehouse advertising. J Hosp Market Manag 25(2):167-196

28. Schouten AP, Janssen L, Verspaget M (2020) Celebrity vs. influencer endorsements in advertising: the role of identification, credibility, and product-Endorser fit. Int J Advert 39 (2):258-281

29. Yuan S, Lou C (2020) How Social media influencers foster relationships with followers: the roles of source credibility and fairness in parasocial relationship and product interest. $\mathrm{J}$ Interact Advert 1-42

30. Horton D, Richard Wohl R (1956) Mass communication and para-social interaction: Observations on intimacy at a distance. Psychiatry 19(3):215-229

31. Hwang K, Zhang Q (2018) Influence of parasocial relationship between digital celebrities and their followers on followers' purchase and electronic word-of-mouth intentions, and persuasion knowledge. Comput Hum Behav 87:155-173

32. Lee JE, Watkins B (2016) YouTube vloggers' influence on consumer luxury brand perceptions and intentions. J Bus Res 69(12):5753-5760

33. Shan Y, Chen KJ, Lin JS (2020) When social media influencers endorse brands: the effects of self-influencer congruence, parasocial identification, and perceived endorser motive. Int $\mathbf{J}$ Advert 39(5):590-610

34. Braverman J (2008) Testimonials versus informational persuasive messages: the moderating effect of delivery mode and personal involvement. Commun Res 35(5):666-694

35. Li SR, Ong YX, Ito N (2020) Credibility in question: travel information adoption among Chinese consumers in Canada and Singapore. In: Neidhardt J, Wörndl W (eds) Information and communication technologies in tourism 2020. Springer, Cham, pp 79-91. https://doi. org/10.1007/978-3-030-36737-4_7

36. Zheng D, Luo Q, Ritchie BW (2021) Afraid to travel after COVID-19? Self-protection, coping and resilience against pandemic 'travel fear.' Tour Manage 83:1-13

37. UNWTO. https://www.unwto.org/country-profile-outbound-tourism. Accessed 15 Jul 2021

38. PRNewswire. https://www.prnewswire.com/ru/press-releases/japan-invites-30-powerfulinfluencers-from-20-foreign-countries-and-regions-in-bid-to-receive-40-677596973.html. Accessed 15 Jul 2021 
39. Seah S, Hoang TH, Martinus M, Pham TPT The State of Southeast Asia: 2021. ISEASYusof Ishak Institute, Singapore. https://www.iseas.edu.sg/wp-content/uploads/2021/01/ The-State-of-SEA-2021-v2.pdf. Accessed 29 Sept 2021

40. Hair JF, Hult GTM, Ringle C, Sarstedt M (2016) A primer on partial least squares structural equation modeling (PLS-SEM). Sage, Thousand Oaks

41. Henseler J, Ringle CM, Sarstedt M (2014) A new criterion for assessing discriminant validity in variance-based structural equation modeling. J Acad Mark Sci 43(1):115-135. https://doi.org/10.1007/s11747-014-0403-8

42. Hair JF, Anderson RE, Tatham RL, Black WC (1995) Multivariate data analysis. PrenticeHall, Englewood Cliffs

43. Cohen J (2013) Statistical power analysis for the behavioral sciences. Routledge, New York

44. Chin WW (1998) The partial least squares approach to structural equation modeling. In Marcoulides, GA (ed) Modern methods for business research. Lawrence Erlbaum Associates, Mahwah

45. Leite FP, Baptista PDP (2021) The effects of social media influencers' self-disclosure on behavioral intentions: the role of source credibility, parasocial relationships, and brand trust. J Market Theory Pract 1-17

46. Gholamhosseinzadeh MS, Chapuis JM, Lehu JM (2021) Tourism netnography: how travel bloggers influence destination image. Tourism Recreat Res 1-17

Open Access This chapter is licensed under the terms of the Creative Commons Attribution 4.0 International License (http://creativecommons.org/licenses/by/4.0/), which permits use, sharing, adaptation, distribution and reproduction in any medium or format, as long as you give appropriate credit to the original author(s) and the source, provide a link to the Creative Commons license and indicate if changes were made.

The images or other third party material in this chapter are included in the chapter's Creative Commons license, unless indicated otherwise in a credit line to the material. If material is not included in the chapter's Creative Commons license and your intended use is not permitted by statutory regulation or exceeds the permitted use, you will need to obtain permission directly from the copyright holder.

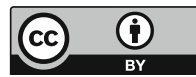

